\title{
INFLUÊNCIA DA PROFUNDIDADE E O DESPOLPAMENTO NA GERMINAÇÃO DE PALMITO JUÇARA (EUTERPE EDULLIS MART.)
}

\author{
Graziela Evencio de Oliveira ${ }^{1}$ \\ Gustavo Ferreira Valani ${ }^{2}$ \\ Paloma Francisca Pancieri ${ }^{3}$ \\ Amanda Duim Ferreira ${ }^{4}$ \\ Fabio Oseias dos Reis Silva ${ }^{5}$
}

Resumo: A exploração do palmito Juçara, tem ocorrido de forma extrativista e predatória para a obtenção do palmito, interferindo na reprodução dessa palmeira. Outro fator que interfere nessa reprodução é presença de substancias inibidoras na polpa. O presente trabalho teve como objetivo avaliar os efeitos da profundidade das sementes no substrato e uso de despolpamento. Os parâmetros avaliados foram: \% germinação e o IVG (índice de velocidade de germinação. O delineamento foi inteiramente casualizado no sistema fatorial 2x2 (sem polpa e com polpa x sobre areia e entre areia). Cada tratamento foi composto por quatro repetições e cada repetição por 25 sementes. Os tratamentos foram dispostos da seguinte forma: (T1) sem polpa e sobre areia, (T2) com polpa e sobre areia, (T3) sem polpa e entre areia e (T4) com polpa e entre areia. Os dados foram submetidos a análise de variância e comparados pelo teste de Tukey a 1\% de probabilidade, utilizando o programa estatístico Assistat. Concluindo-se que a melhor profundidade é sobre areia com as sementes despolpadas.

Palavras-chaves: Arecaceae; Umidade; Substrato.

\footnotetext{
${ }^{1}$ Agronomia/Universidade Federal do Espírito Santo, Brasil. E-mail: grazievencio_@hotmail.com.

2 Agronomia/Universidade Federal do Espírito Santo, Brasil. E-mail: gustavo.valani@hotmail.com.

${ }^{3}$ Agronomia/Universidade Federal do Espírito Santo, Brasil. E-mail: paloma.panci@hotmail.com.

${ }^{4}$ Agronomia/Universidade Federal do Espírito Santo, Brasil. E-mail: amanda.duim@hotmail.com.

${ }^{5}$ Agronomia/Universidade Federal do Espírito Santo, Brasil. E-mail: foseias_ufrrj@hotmail.com.
} 